\title{
ENRIQUE Vila-MATAS, ENTRE LEGÍVEL E ILEGÍVEL: UMA POÉTICA EM FORMA DE FICÇÃO
}

\section{Gisela Bergonzoni}

"Chet Baker piensa en su arte: ficción crítica", publicado pela primeira vez em 2011 na antologia de contos Chet Baker piensa en su arte, de Enrique Vila-Matas, tem como narrador um crítico literário que se tranca em um quarto de hotel em Turim, com uma complexa missão: teorizar e ao mesmo tempo inaugurar um novo gênero literário, que ele nomeia "ficção crítica". Esse gênero misturaria as figuras de Monsieur Hire e de Finnegans, ou seja, a narrativa de Georges Simenon (exemplificada pela famosa novela Les fiançailles de monsieur Hire, de 1933, adaptada diversas vezes à televisão e ao cinema) e o texto experimental de James Joyce (cujo romance Finnegans Wake, publicado em 1932, está entre seus escritos mais obscuros e inovadores).

O narrador de Vila-Matas constata uma crise da narrativa, provocada pela literatura moderna, que desvirtuou as formas tradicionais de representação. Hiperconsciente e próxima da teoria, a literatura passa a tematizar a própria crise da mímesis, expulsando a intriga, os personagens e até mesmo o autor. Porém, o narrador não deseja apenas restaurar a literatura narrativa tradicional, impassível diante da modernidade e dos questionamentos colocados pela teoria literária. Ele tem como ambição reunir em uma única escrita dois mundos diversos: o dos escritores Finnegans (entre os quais, além de Joyce, encontram-se Beckett, John Banville, Lobo Antunes e outros) e o dos Hire (Simenon, Gabriel García Marques, Graham Greene). A novela se desenvolve como um diário íntimo-crítico, no qual o narrador reflete sobre a forma a dar a uma escrita 
ao mesmo tempo "legível" e "ilegível". No entanto, pergunta-se o narrador, “ ¿cómo reconciliar realidad y ficción logrando encima que ésta, al pasar a ser tan salvaje e indescifrable como la realidad, se vuelva de pronto, ante nuestros maravillados ojos, plenamente legible?" (VILA-MATAS, 2011a, p. 259). ${ }^{1}$

Compreende-se, com o trecho reproduzido acima, que a ficção seria ligada ao texto legível, enquanto a realidade estaria no campo do ilegível. Um breve exame do uso da palavra "realidade" em oposição à "ficção" se faz necessário. Enquanto seria mais lógico associar o legível ao realismo, na "ficção crítica" de Vila-Matas a busca pela realidade é radicalizada pela escrita experimental. As duas tendências, o legível e o ilegível, têm em suma o mesmo objetivo, ainda que os caminhos percorridos para o realizar sejam opostos. De um lado, os Hire querem dar um sentido ao fluxo incompreensível dos acontecimentos da vida por meio da narrativa; do outro, os Finnegans desejam dar voz à existência em sua forma insensata e desconexa. Mas em que sentido seria mais lógico associar realidade a legibilidade? Faço recurso aqui a Philippe Hamon (1974), que em um estudo estilístico do romance define a narrativa realista como a que contém o mais alto grau de legibilidade. No texto "Note sur les notions de norme et de lisibilité en stylistique", o autor estuda primeiramente a relação conflituosa da estilística com o conceito de "norma”: ele lembra que a disciplina conheceu fases normativas, mas alargou seu entendimento a partir do momento em que passou a questionar a neutralidade da norma. Hamon explora as diferentes correntes da estilística que contribuíram para uma concepção mais dinâmica do texto, relativizando a distância entre norma e desvio. Buscando integrar essas diferentes concepções, o autor propõe substituir a noção de "norma" pela de "legibilidade" [legibilité]: o legível, segundo ele, comporta elementos externos ao texto (psicológicos, culturais e linguísticos) e reside também numa lógica interna, construída (ou demolida, no caso da ilegibilidade) sucessivamente dentro do texto e pelo próprio texto:

Serait lisible quelque chose qui nous donnerait la sensation du déjà vu (ou déjà lu, ou déjà dit, par le texte ou par l'extra-texte diffus de la culture); serait illisible un texte qui s'écarterait de ce déjà vu. On récupérerait, ainsi, sous ce concept unifiant, les phénomènes de la mémoire, de la culture, et de la rétroaction

\footnotetext{
1 “[...] como conciliar realidade e ficção de modo que esta, ao se tornar tão selvagem e indecifrável como a realidade, transforme-se de repente, diante de nossos maravilhados olhos, plenamente legível?"
} 
(quand, où et comment le lecteur "revient-il en arrière" dans son parcours du texte ?) qui sont en général exclus d'une stylistique trop rigoureusement formaliste et descriptive; on récupérerait la notion "d'intercompréhension" utilisée par les linguistes, en même temps qu'on évacuerait les connotations toujours possibles soit de la norme, soit de l'écart [...] (HAMON, 1974, p. 120).

O texto legível, para o autor, é o que provoca a sensação do déjà vu, o que reúne tanto uma concepção formalista e imanente de legibilidade (um texto constrói sua própria legibilidade) quanto uma concepção linguística, que pensa o texto como uma superposição de estratos ou registros. O autor propõe em seguida um quadro de critérios que tornariam um romance mais ou menos legível. Entre os critérios internos, Hamon (1974, p. 121) lista, para o mais alto grau de legibilidade, "l'organisation logique, sémantique et linguistique du texte à tous ses niveaux",3 o que implica um funcionamento normal das anáforas, o respeito às regras de concordância e uma inclinação à monossemia dos termos (ou seja, ao sentido próprio, ao invés do figurado). Um texto legível é autônomo, pois evita as referências a situações concretas de discurso; ele elide também formas modais e shifters, assim como "intrusões do autor" [intrusions d'auteur] (HAMON, 1974, p. 121). A legibilidade é preservada, ainda, por um suporte escrito homogêneo e estável, que se traduz pela ortografia, a tipografia e a ordem de leitura da esquerda para a direita. Quanto a critérios externos, ele destaca como objetos centrais do discurso legível: a realidade ou o "verossímil referencial" [vraisemblable référentiel] (p. 121), o que torna a narrativa realista o texto mais legível de todos; a relação do texto com uma ideologia, que o autor chama de "verossímil cultural" [vraisemblable culturel] (p. 121), e que poderíamos definir como uma reprodução do senso comum; e o pertencimento do texto a um gênero literário reconhecível, o "verossímil estético" [vraisemblable esthétique] (p. 121).

\footnotetext{
2 "Seria legível alguma coisa que nos desse a sensação do déjà vu [já visto] (ou do já lido, ou já dito, pelo texto ou pelo extratexto difuso da cultura); seria ilegível um texto que se afastasse desse já visto. Seria possível recuperar, assim, com esse conceito unificador, os fenômenos da memória, da cultura e da retroação (quando, onde e como o leitor 'volta atrás' no seu percurso do texto?) que são geralmente excluídos de uma estilística muito rigorosamente formalista e descritiva; Seria possível recuperar a noção de 'intercompreensão' utilizada pelos linguistas e, ao mesmo tempo, esvaziar as conotações sempre possíveis, seja da lacuna, seja do desvio." 3 “[...] a organização lógica, semântica e linguística do texto em todos os seus níveis."
} 
Para o narrador de Vila-Matas em "Chet Baker piensa en su arte", o texto ilegível, contrariamente ao que preconiza Vila-Matas (2011a, p. 259), seria o que mais se aproxima do realismo, porque ele é "tan salvaje e indescifrable como la realidad". ${ }^{4}$ Nesse sentido, é pertinente aproximar a oposição da qual trata o narrador de Vila-Matas de algumas distinções feitas por Roland Barthes, primeiramente entre "récit" [relato] e "écriture" [escritura] - em Le degré zero de l'écriture (2002a) - e, mais tarde, entre "lisible" [legível] e "scriptible" [escrevível] - em S/Z (2002b), ensaio sobre a novela Sarrasine, de Balzac. Como forma literária instituída no século XIX, a narrativa tradicional, o "récit", explica e ordena a existência humana, enquanto a escritura moderna, a "écriture", busca fraturar todo sentido possível. Por meio do uso do passado simples - lembrando que Barthes fala dos tempos verbais em francês -, a narrativa transmite a ideia de que o conjunto de fatos narrados produz uma significação. Por outro lado, a escritura moderna, que usa, sobretudo, os tempos presente e passado composto, traduz a instabilidade e a incerteza: "La modernité commence avec la recherche d'une Littérature impossible. [...] Ce qu'il s'agit de détruire, c'est la durée, c'est-à-dire la liaison ineffable de l'existence" (p. 194). 5

Em $S / Z$ (BARTHES, 2002b), o texto legível é o "clássico", aquele que não se abre à criação do leitor, configurando a leitura como um simples referendo do que foi escrito. O texto "scriptible", por outro lado, transforma o leitor em produtor, que escreve à medida que lê. Enquanto texto clássico, que propõe a representação de algo, Sarrasine de Balzac é um texto legível. Mas, segundo Barthes (2002b, p. 129), ele conserva uma pluralidade parcial - que o crítico francês se propõe a analisar por meio das centenas de "lexias" [lexies], unidades mínimas de sentido, que ele identifica na novela. O método de leitura de $S / Z$, portanto, aplica-se a um texto legível que possui regiões obscuras, "scriptibles", as quais cabe ao crítico identificar para estilhaçá-las em múltiplas interpretações. O objetivo da crítica proposta por Barthes não é o de encontrar um sentido de um texto, mas de afirmar sua pluralidade.

Evoco aqui mais um binômio barthesiano, menos conhecido, que se aproxima e ao mesmo tempo se diferencia dos dois apresentados acima: aquele que distingue entre "legível" e "ilegível", abordado brevemente

\footnotetext{
4 "[...] tão selvagem e indecifrável como a realidade."

5 "A modernidade começa com a busca de uma Literatura impossível. O que se trata de destruir é a duração, isto é, a ligação inefável da existência."
} 
na última aula do curso La préparation du roman, que o autor ministrou no Collège de France, entre dezembro de 1978 e fevereiro de 1980, pouco antes do atropelamento que levou à sua morte. Nesse curso, Barthes simula a escrita de um "Romance" - uma obra sem gênero definido, mas que ele nomeia "Romance", com "R" maiúsculo, para diferenciá-la de seus escritos precedentes - com o objetivo de investigar a criação literária como prática. No fim do curso, ele caracteriza a obra que gostaria de escrever: ela teria simplicidade, filiação e desejo. É o primeiro preceito que nos interessa para a presente reflexão: uma das características da obra simples seria justamente ser "legível". Aqui, legível não se opõe a "scriptible", diferentemente de $S / Z$, mas a "ilegível". O autor faz uma breve alusão à noção de legibilidade de Philippe Hamon (2015, p. 546), explicitada acima, para resumi-la em seguida em seu próprio conceito: o texto legível que ele deseja escrever seria aquele dotado de uma "armação narrativa” [armature narrative], ou seja, aquele em que os esquemas discursivos constroem uma estrutura coerente, e também dotado de um "sistema anafórico não deceptivo" [système anaphorique non déceptif] (p. 546). A anáfora, na retórica, é a repetição de um elemento do sintagma precedente. A legibilidade é garantida pela correspondência entre esses elementos: quando um texto menciona "o homem", o leitor deve saber de que homem se trata. O sistema anafórico, diz Barthes (2015, p. 547), pode ser "provisoriamente deceptivo" [provisoirement déceptif]. Mas a manutenção dessa decepção provoca o sentimento de ilegibilidade, uma espécie de "vertigem lógica" [vertige logique] (p. 547). "Ilegível”, aqui, não corresponde inteiramente ao "scriptible" de $S / Z$ : enquanto este configura uma constelação de leituras possíveis, aquele se refere a um problema de compreensão.

Como explicar que Barthes retome uma ideia de legibilidade sem, contudo, fazer referência a seus próprios estudos de Sarrasine? Pode-se dizer que essa transformação da concepção de "legível", presente em La préparation du roman, deve-se ao deslocamento, de certa forma, do ponto de vista da análise textual (caso do exame das lexias de Sarrasine, proposto em $S / Z$ ) para o da criação literária. O autor está interessado aqui em como escrever uma obra legível, e não mais em analisar os pontos obscuros de um texto legível.

O narrador de "Chet Baker...", ao opor o texto "legível" ao "ilegível", identifica a capacidade da escritura, no sentido barthesiano, de desestabilizar e ao mesmo tempo abrir para uma multiplicidade de 
leituras. Sua ideia de "legível" condensa, de certa maneira, as três concepções de "legível" que destaquei ao longo da obra de Barthes. Antes de problematizarmos a oposição de Vila-Matas, é importante avançarmos na leitura de sua novela para que se entendam melhor as forças em jogo.

Múltiplas referências intervêm em "Chet Baker piensa en su arte", mas podem-se identificar dois intertextos principais: primeiramente, a aventura imóvel de Voyage autour de ma chambre, de Xavier De Maistre (1795), na qual o narrador reflete sobre a dualidade do homem, dividido entre sua "alma" e sua "besta". Enquanto a alma é o espírito capaz de viajar sem amarras, a besta se ocupa das tarefas mecânicas, como caminhar e comer. Também em primeiro plano, há The Strange Case of Dr. Jekyll and Mr. Hyde, de Robert Louis Stevenson (1886), que igualmente põe em cena a divisão do sujeito entre duas personalidades: um cientista usa a si mesmo como cobaia para experimentos que o transformam de tempos em tempos em um homem vulgar e violento. No intuito de misturar as duas tendências literárias que vê como opostas, o narrador de "Chet Baker..." começa a explorar seu lado Hire, sofrendo uma mutação química como a de Dr. Jekyll e se transformando em Mr. Hyde: ao estimular a pequena parcela terrível de sua personalidade, o médico acaba por ser dominado pelo seu duplo monstruoso. Da mesma forma, o narrador-personagem de Vila-Matas sente progressivamente vontade de ler e escrever histórias simples, de se identificar com personagens, de seguir uma intriga.

A instância narrativa enfrenta mudanças complexas ao longo da novela de Vila-Matas, as quais simulam a gradual dominação do narrativo sobre o não narrativo. No vigésimo quinto capítulo, que marca o meio da trama, há uma reviravolta. É o único momento em que intervém a figura de Chet Baker, que dá título à novela. Pela janela de seu quarto de hotel, o narrador observa dois mendigos bêbados discutindo, os quais ele imagina serem Finnegans e Hire. Ao lado deles, vê um homem fumando dentro de um carro. Esse homem, pensa o narrador, seria uma réplica de si mesmo, que observa as duas criaturas e tenta fundi-las em uma única. Ele poderia ser, ainda, Chet Baker: o crítico se lembra de que em Nova York, quando se via um homem fumando em um carro estacionado, dizia-se que era o trompetista pensando em sua arte. Essa "unidad vagabunda" (VILAMATAS, 2011a, p. 313), uma combinação de várias projeções do narrador, sobe então em direção ao quarto para encontrar seu duplo. O narrador se transforma, em seguida, em um outro "eu", que se refere ao crítico na 
terceira pessoa do singular e que o observa do exterior, como a "alma" olha a "besta", de modo semelhante ao trabalhado na novela de De Maistre:

Puedo imaginarme a un crítico que, inmerso en el vago flotar de una noche de su vida, intenta escribir una larga pieza de un género que él llama "ficción crítica" $y$, casi sin darse cuenta y con la contrariedad inicial que esto le representa, se convierte en el observador y potencial narrador de una historia tradicional, con personajes (VILA-MATAS, 2011a, p. 310). ${ }^{6}$

Esse desdobramento da instância narrativa parece apontar para a figura do autor: Vila-Matas, como Chet Baker na anedota nova-iorquina, pensa em sua arte, que sintetiza sua busca por uma literatura narrativa e ao mesmo tempo crítica. Ele assume os traços de Chet Baker para olhar para sua própria novela, do lado de dentro. O autor, segundo a leitura que proponho, é observado por seu narrador através da janela, como se fosse um personagem, e acaba por unir-se a ele, num estranho amálgama. Essa interpretação explicaria a importância do nome do trompetista, que aparece de maneira alusiva na novela, mas que ao mesmo tempo lhe fornece o título. "Chet Baker" possui, aqui, a função de um pseudônimo, mesmo que ele figure no título, e não no lugar do nome do autor: o personagem real do trompetista não chega a aparecer de fato na trama, limitando-se a emprestar seu nome a Vila-Matas. Ao fazê-lo, o autor se desvencilha do pacto autobiográfico (LEJEUNE, 1975) e realiza uma poética em forma de ficção - ou de ficção crítica, como veremos a seguir.

A dualidade sobre a qual se debruça Vila-Matas não corresponde apenas à postura de um escritor diante da realidade, encarando-a como um objeto apreensível e passível de organização estruturada e de sentido (no caso dos escritores legíveis), ou como uma massa disforme e desprovida de significado, da qual só se pode reproduzir a inconstância (no caso dos ilegíveis). Trata-se também de um embate entre crítica literária, ou ensaio, e narração supostamente "pura". Não se trata de uma oposição nítida, como se o ensaio correspondesse ao ilegível e o romance, ao legível, mas da ideia de certa assimilação da teoria pela criação. A ilegibilidade é fruto da hiperconsciência da literatura modernista, que incorpora a crítica de si mesma e passa a enxergar sua matéria-prima, a linguagem, como opaca. Ao mesmo tempo, a crítica literária se coloca ao lado dessa literatura

\footnotetext{
6 "Posso imaginar um crítico que, imerso no vago flutuar de uma noite de sua vida, tenta escrever uma extensa peça de um gênero que ele chama 'ficção crítica' e, quase sem se dar conta e com a contrariedade inicial que isso representa pra ele, converte-se no observador e potencial narrador de uma história tradicional, com personagens."
} 
ilegível, pois se interessa pelos textos que suscitam problemas a serem analisados e desdenha a leitura confortável e apaziguante.

Vila-Matas extrai grande parte de sua obra dessa tensão entre teoria e prática literárias, entre leitura crítica e escrita. Isso não está apenas na forma de seus escritos, que constantemente cruzam ficção e ensaio literário, mas também nos temas que despontam em sua obra. Proponho aqui dois exemplos que ilustram como o conflito entre teoria e ficção é o próprio objeto literário de Vila-Matas, um extraído de Bartleby y compañía (200o) e outro de Dublinesca (2010a). Em ambos, Barthes tem um papel de figurante que não deixa de ser notável.

Bartleby y compañía (VILA-MATAS, 200o) é um dos mais contundentes casos de hibridização na obra de Vila-Matas. Trata-se de um romance narrado por um funcionário de escritório, afastado do trabalho e que ocupa seu tempo pesquisando sobre artistas e escritores que, a exemplo do escrivão do conto de Herman Melville, preferiram dizer "não" e pararam de escrever ou produzir obras. O livro se estrutura como um ensaio, que enumera casos reais de "bartlebysmo" (Rimbaud, Marcel Duchamp), com detalhes biográficos, análises e citações de leituras críticas, mas também inclui personagens fictícios, como María Lima Mendes. Esta talentosa luso-cubana, que o narrador conhece em uma estadia em Paris nos anos 1970, tenta escrever seu primeiro romance, mas é acometida por um estranho mal, o "chosisme": excessivamente influenciada pelas incursões experimentais do Nouveau roman e pela leitura da revista vanguardista Tel Quel, María se sente bloqueada. É um artigo de Barthes, "Par où commencer" [Por onde começar], que mina qualquer germe de escrita criativa.

Em Dublinesca (VILA-MATAS, 2010a), Samuel Riba, um editor em crise, viaja à Irlanda para celebrar tristemente o funeral da era Gutenberg, o fim do livro impresso e o advento da era Google. Mas esse percurso também tem como objetivo se libertar da sua francofilia - como diagnostica um amigo, Riba é impregnado em demasia de french theory e precisa dar um "salto inglés" (2010a, p. 67). De fato, sua juventude é marcada pela "morte do autor": o célebre texto de Barthes, de 1967, decretando o fim do império autoral o deixa desesperado, imaginando que não haverá mais escritores. Como uma espécie de anexo teórico de Dublinesca, Vila-Matas (2010b) lançou, no mesmo ano, um curto volume intitulado Perder teorías, em que o narrador em primeira pessoa (uma segunda versão de Samuel Riba, aqui escritor, e não editor) viaja a Lyon e escreve um pequeno compêndio sobre 
o romance do futuro, para, no fim, jogá-lo fora. Para escrever, entende o narrador, é preciso "perder teorías, perderlas todas" [perder teorias, perdê-las todas] (VILA-MATAS, 201ob, p. 64).

Porém, tanto em Bartleby... como em Dublinesca, o embate é incessante e contraditório: não há uma verdadeira dicotomia entre ficção e ensaio, mas uma dialética. No caso do "bartlebysmo" de María, o recurso de Vila-Matas para expor o embate é a ironia: o caso parodia certo discurso humanista que desqualifica o estruturalismo e a nouvelle critique como responsáveis pela crise da literatura. ${ }^{7}$ Em Dublinesca e em Perder teorías, o autor também brinca com os lugares comuns sobre a french theory, e a teoria é um obstáculo apenas na aparência, revelando-se uma condição fundamental para a escrita - é necessário ter teorias para poder perdê-las.

No final de "Chet Baker piensa en su arte", também teoria e ficção permanecem em tensão, e a tentativa de fusão de gêneros aparentemente fracassa: não há conciliação entre Finnegans e Hire. A novela termina com o novo narrador, Finnegans, que observa o antigo narrador (o crítico literário, dominado agora por sua parcela Hire) se esvanecendo num horrível torpor. Como ressalta o narrador de Vila-Matas (2011a, p. 309), "lo notable del texto de Stevenson es que no resuelve la contradicción, sino que mantiene los dos elementos - vida y muerte - en eterno presente”. ${ }^{8}$ É o que acontece em "Chet Baker...”: o legível e o ilegível permanecem em um constante embate, sem que o crítico consiga unir as duas escrituras. No entanto, é dessa tensão que nasce a narrativa: porque, se a "ficção crítica" não se realiza em uma perspectiva interna, pelo narrador-personagem, ela é lograda por meio do autor. No subtítulo de "Chet Baker piensa en su arte", encontra-se precisamente a menção "ficción crítica”, entre parênteses, o que indica, por um efeito de mise-en-abyme, que estamos lendo a novela que o personagem está escrevendo. A menção "ficción crítica” assumiria aqui o valor de indicação "paragenérica”, segundo a terminologia de Gérard Genette (1987), que, no estudo do paratexto proposto em Seuils, analisa a tipologia e a função dos títulos. A indicação paragenérica comunica um gênero inventado ou inovador, a exemplo das "Situações" de Sartre. Isso denota que a ambição do crítico narrador de "Chet Baker..." corresponde à de seu autor: fundar um novo gênero literário.

\footnotetext{
7 Esse aspecto é desenvolvido no artigo "Vila-Matas pense à son art: entre l'âme et la bête, entre la critique et le récit" (BERGONZONI, 2016).

8 "O importante do texto de Stevenson é que não resolve a contradição, apenas mantém os dois elementos - vida e morte - em eterno presente."
} 
Em "Chet Baker..., Vila-Matas mostra que, apesar da perda de inocência do romance e da novela, ainda é possível narrar. Sob a forma de uma "ficção crítica", o escritor transforma um problema teórico em impulso criativo. Consciente da opacidade da linguagem, o escritor pode reencontrar a narrativa sob uma nova perspectiva. E é a história do fracasso da união entre o legível e o ilegível, entre narrativa e crítica, que pode agora ser contada.

Para entender como Vila-Matas transpõe esse obstáculo, é interessante evocar Barthes, mais uma vez. Na conferência "Longtemps, je me suis couché de bonne heure" [Durante muito tempo, deitei-me cedo], pronunciada no Collège de France em outubro de 1978, Barthes propõe uma leitura da grande obra de Proust como fruto do embate entre duas escritas: a crítica e a ficção. A conferência prefigura diversos problemas que o crítico abordaria no curso "La préparation du roman", que começaria dois meses mais tarde: ele busca apreender o que levou Proust a abandonar a redação de seu ensaio Contre Sainte-Beuve - que foi publicado postumamente, em 1954 - para iniciar a escrita de $\hat{A}$ la recherche du temps perdu (1920). Segundo a leitura de Barthes, enquanto redigia Contre Sainte-Beuve, Proust teria hesitado entre um ensaio combativo e um romance que contradiria os propósitos de Sainte-Beuve em sua própria forma. Mesmo que Proust tenha abandonado seu ensaio em nome da escrita romanesca, esta comporta traços importantes da escritura ensaística, baseada na desorganização do tempo. Barthes chama a Recherche de uma "terceira forma" [tierce forme], que conta não a vida do narrador, mas o desejo de escrever.

Quand il [Proust] s'est mis à écrire ce qu'il a produit c'est une Tierce Forme [...], ni roman ni essai ou les deux à la fois, à savoir la Recherche, et il n'a pu commencer à écrire son œuvre précisément qu'en abandonnant la rigidité du code fantasmatique. Le Fantasme [...], c'est comme une énergie, comme un moteur qui met en marche, mais ce qu'il produit ensuite, réellement, ne relève plus du code (BARTHES, 2015, p. 35).9

Segundo Barthes, Proust consegue chegar à Recherche somente quando ele supera os "Fantasmas", as concepções que aprisionam o

\footnotetext{
9 "Quando ele [Proust] se pôs a escrever, o que ele produziu foi uma Terceira Forma, nem romance nem ensaio, ou os dois ao mesmo tempo, a saber, La recherche, e ele só pôde começar a escrever sua obra precisamente ao abandonar a rigidez do código fantasmático. O Fantasma [...] é como uma energia, como um motor que começa a funcionar, mas o que ele produz em seguida, na verdade, já não faz parte do código."
} 
romance e o ensaio em categorias rígidas. Embora seja necessário passar primeiramente por esses "Fantasmas", lutar contra eles e elaborá-los, o resultado, a escrita em sua materialidade, escapa aos gêneros prédefinidos. Essa ideia de Barthes ilustra o movimento feito por Vila-Matas em "Chet Baker piensa en su arte", que encena o fantasma da escrita sob a forma de uma hesitação entre duas concepções rígidas, a de texto legível e a de texto ilegível. Ambas as escritas seriam, na verdade, "convenções mortas" para o narrador de Vila-Matas (2011a, p. 288): "Puedo verme desde fuera como un doctor Frankenstein captado en el preciso momento de proceder a la unión de los cadáveres diseccionados de dos géneros literarios que habrían terminado por ser dos convenciones muertas: el realismo y el experimentalismo radical". ${ }^{10}$

É como se o narrador de Vila-Matas ficasse preso no fantasma, impotente diante da incompatibilidade entre uma escrita crítica, que se aproximaria do ensaio, e uma escrita narrativa "pura”, que se aproximaria do romance ou novela. No lugar do narrador, é o autor que entra no "real da escrita" [réel de l'écriture], para usarmos a expressão de Barthes (2015, p. 34) sobre a crise de Proust. É o autor que consuma a "ficção crítica", superando os "fantasmas" rígidos dos gêneros literários e realizando uma obra que os transborda. Assim como, na Recherche, o narrador de Vila-Matas sonha em escrever um livro que é escrito por seu autor. Porém, enquanto em Proust há uma promessa de escrita que se traduz na epifania do narrador no final do último volume da Recherche - Le temps retrouvé -, em Vila-Matas é sobre o aparente malogro da escrita que a narrativa é construída.

Vila-Matas realiza o desejo de seu próprio narrador, propondo uma novela ao mesmo tempo legível e ilegível, embora esses dois elementos, como substâncias químicas incompatíveis, não se fundam. É importante, agora, confrontarmos o texto do autor com as concepções de legível e ilegível que foram apresentadas no início deste artigo. No que toca à estrutura, Vila-Matas realiza em parte o projeto de legibilidade que Barthes imagina para sua obra em La préparation du roman: ele dá à sua novela uma "armação narrativa”, o que poderia qualificá-la como uma narrativa intelectual - como Barthes classifica narrativas que não relatam

\footnotetext{
1o "Posso me ver, a partir de fora, como um doutor Frankenstein captado no preciso momento de proceder à união dos cadáveres dissecados de dois gêneros literários que tinham se transformado em duas convenções mortas: o realismo e o experimentalismo radical."
} 
necessariamente acontecimentos, mas uma progressão mental, à maneira de Monsieur Teste, de Valéry. O sistema anafórico de "Chet Baker...", no entanto, o faz pender para o texto ilegível, pois a instância narrativa é altamente instável, o "eu" sofrendo mutações, desdobrando-se em narrador e personagem, e assumindo diversas formas e nomes ao longo da trama: o crítico, Chet Baker, Hire, Finn, Stanley Elkin (em referência ao escritor americano, autor de George Mills, de 1982), entre outros. O próprio título, "Chet Baker piensa en su arte", é enigmático, pois a figura do trompetista intervém somente em um momento preciso, o que pode ser frustrante para o jogo de expectativas que um texto apresenta ao leitor.

Se "Chet Baker...", quanto à estrutura, opera um dos critérios de legibilidade de Barthes (a armação narrativa) e refuta o outro (o sistema anafórico não deceptivo), resta investigarmos se as acepções de ilegível e legível que se depreendem do texto são compatíveis com as que apresento acima. O que o narrador de "Chet Baker..." entende por legível ou ilegível? Se confrontarmos seu binômio ao apresentado por Barthes em La préparation..., entenderemos que a ideia de legibilidade de VilaMatas é um pouco mais ampla, comportando também critérios externos ao texto. Nesse sentido, ele se aproxima do quadro de legibilidade destrinchado por Philippe Hamon (1974): como critérios externos ao texto, ela traz uma ideologia, fazendo recurso aos clichês, e se filia a um gênero literário preestabelecido e bem definido. Porém, como já afirmado acima, a legibilidade segundo Vila-Matas se distancia da de Hamon no que concerne à relação ao referente. Para o narrador de "Chet Baker...", é o texto ilegível que dá lugar mais plenamente e mais radicalmente ao real, pois ele dá forma à inconstância da vida de maneira mais fiel. É por isso que o conceito de "legível" nessa novela condensa, de certa forma, os três binômios de Barthes: ele é "écriture" em contraste com "récit", ele é "scriptible" em contraste com "lisible". Legível e ilegível correspondem a duas posturas do escritor diante da realidade e também a uma concessão, ou não, a um pensamento acrítico ou ingênuo. $O$ narrador percebe aos poucos que sua incursão no mundo Hire se revela prejudicial para a integridade do seu espírito crítico. O narrativo ou legível é frequentemente descrito na novela como uma máscara, uma farsa, que finge dar sentido ao que não podemos compreender:

La literatura Hire nace de no poder aguantar el desorden atolondrado de la vida. O lo que es lo mismo: si la gran mayoría de los humanos se sienten impulsados a abandonar parcialmente el área Finnegans, es porque intuyen que su locura 
podría ir progresando sin cesar. Entonces organizan todo esto, organizan un sentido, se acogen al sillón de orejeras Hire. La literatura de ese estilo, la literatura Hire, simula que cree en el sentido, y en los vientos atolondrados del desorden se dedica a construir pequeños teatros fijos, mínimos teatros estables, teatrillos del alma, sucesos narrables; construye estilos propios, estilos que son farsas armadas sobre la nada. Y todo para no desesperar, para no caer en el sinsentido más absoluto (VILA-MATAS, 2011a, p. 342). ${ }^{11}$

Mesmo que o narrativo possa parecer ameaçador, o narrador de VilaMatas (2011a, p. 256) também não se contenta com sua posição de crítico, e sua "más profunda poética" reside na própria tentativa de conciliar ficção e ensaio, no esforço de incorporar alguns aspectos Hire, algumas feições de romancista. Uma empreitada análoga à de Barthes em La préparation du roman, que usa a transmutação do ensaio em romance na obra de Proust (do Contre Sainte-Beuve à Recherche) para imaginar uma escrita criativa derivada da ensaística e para tentar entender como uma escrita fragmentária é combinada de maneira a resultar em uma forma longa. Os "Fantasmas" do romance e do ensaio, que impediam Proust de escrever, são, segundo vimos acima em Barthes, uma "energia”, que refreia mas ao mesmo tempo impulsiona o autor em direção à escrita real. É o que parece acontecer em "Chet Baker...": conduzido pelos "Fantasmas" dos gêneros literários que assombram seu narrador, Vila-Matas realiza sua "ficção crítica”, que transcende as categorias rígidas para encontrar a escrita em sua materialidade, mobilidade e permanente tensão.

Apesar de Barthes não ser citado nominalmente em "Chet Baker piensa en su arte", contrariamente ao que ocorre em outros escritos de VilaMatas (como Dublinesca, Bartleby y compañía, París no se acaba nunca e alguns textos breves, como "Pensadores de café frío: Roland Barthes", de 1995), o crítico francês está presente não somente nas aproximações que o presente artigo propõe, mas em uma imagem, reproduzida unicamente na edição francesa da novela, Chet Baker pense à son art: fiction critique. Publicada em 2011, mesmo ano de sua primeira edição em espanhol, pela

\footnotetext{
11 "A literatura Hire nasce de não poder aguentar a desordem confusa da vida. Ou, o que dá no mesmo: se a grande maioria dos humanos se sente inclinada a abandonar parcialmente a área Finnegans, é porque intui que sua loucura poderia ir progredindo sem cessar. Então, organizam tudo isso, organizam um sentido, se acomodam nas poltronas das armadilhas Hire. A literatura desse estilo, a literatura Hire, simula que acredita no sentido, e nos ventos confusos da desordem se dedica a construir diminutas cenas fixas, mínimas cenas estáveis, teatrinhos da alma, sucessos narráveis; constrói estilos próprios, estilos que são farsas armadas sobre o nada. E tudo para não se desesperar, para não cair no absurdo mais absoluto."
} 
Mercure de France, a versão francófona de "Chet Baker..." é ilustrada por vinte imagens. Entre elas, retratos de Vila-Matas em diferentes momentos da vida, fotos de escritores citados (Beckett, Joyce), uma página das provas corrigidas de Finnegans Wake, alguns cartazes de filmes (como Monsieur Hire, por Patrice Leconte), fotos de paisagens urbanas (Dublin, Turim) etc. Entre os retratos de escritores, há o de Barthes, por François Lagarde, datado de 1979. Como explicar essa aparição no peritexto de "Chet Baker..., aparentemente sem um ligame explícito com a trama? Se recorrermos ao epitexto [épitexte], segundo a terminologia de Genette (1987), descobriremos que a coleção que abriga essa novela, "Traits et portraits”, é dirigida pela escritora e fotógrafa Colette Fellous e reúne escritores, poetas, cineastas, pintores e estilistas de moda, segundo a descrição do site de Mercure de France. Lê-se ainda que "chacun s'essaie à l'exercice de l'autoportrait. Les textes sont ponctués de dessins, d'images, de tableaux ou de photos qui habitent les livres comme une autre voix en écho, formant presque un récit souterrain" (TRAITS, [s.d.]). ${ }^{12}$

Contrariamente à edição espanhola, em que a novela "Chet Baker..." se eclipsa entre outros textos do autor, ainda que ele dê título à coletânea, a edição francesa o valoriza: como visto acima, fica claro aqui que se trata de um exercício de autorretrato do autor - uma poética de Vila-Matas, que se autofigura em Chet Baker pensando em sua arte. Com efeito, as imagens parecem contar uma segunda história, cuja relação com a trama nem sempre é explícita. Barthes assegura, com sua presença imagética, um lugar fundamental na poética de Vila-Matas, sobretudo porque encarna a hesitação entre a vanguarda e o romance tradicional, e também entre a crítica e a ficção, que está presente em muitos de seus escritos e que é a própria matéria da novela em questão.

Na foto, Barthes está sentado sobre sua cama e olha pela janela, o que traz à mente uma passagem-chave de "Chet Baker piensa en su arte": no vigésimo quinto capítulo, quando um segundo narrador suplanta o crítico literário, que se torna um simples personagem, este se levanta, cansado de seu trabalho infrutífero sobre a "ficção crítica", e se aproxima da janela. Ele vê suas duas projeções, Hire e Finnegans, assim como o próprio autor, transfigurado em Chet Baker e fumando em seu carro. Como analisamos acima, esse momento manifesta a transformação do narrador e marca a

\footnotetext{
12 "[...] cada um pratica o exercício do autoretrato. Os textos são pontuados de desenhos, de imagens, de quadros ou de fotos que habitam os livros como uma outra voz em eco, formando quase um relato subterrâneo."
} 
entrada do autor na história: aquele que, ao contrário do seu narrador, logrou sua "ficção crítica". A imagem de Barthes, que pontua a novela de Vila-Matas de maneira fantasmática (um pouco como Chet Baker, esvaziado de sua biografia real para funcionar como um pseudônimo), evoca-nos novamente La préparation du roman. É como se o fotógrafo houvesse captado um momento preciso, em seu apartamento em Paris, - em 1979, ano em que Barthes se dedicava à segunda fase de seu último curso no Collège de France -, no qual o crítico, enquanto olhava pela janela, sonhava em como unir o ensaio e o romance, e em como fusionar o ilegível com o legível.

\section{REFERÊNCIAS}

BARTHES, Roland. Le degré zéro de l'écriture. In: Euvres complètes, t. I. Livres, textes, entretiens, 1942-1961. Paris: Seuil, 2002a[1953].

BARTHES, Roland. S/Z. In: CEuvres complètes, t. III. Livres, textes, entretiens, 1968-1971. Paris: Seuil, 2002b[1970].

BARTHES, Roland. La préparation du roman. Cours au Collège de France, 1978-79 et 19798o. Paris: Seuil, 2015[2003].

GENETTE, Gérard. Seuils. Paris: Gallimard, 1987. (Col. Poétique)

HAMON, Philippe. Note sur la notion de norme et lisibilité en stylistique. In: Littérature. L'effet littéraire, n. 14, 1974, pp. 114-122.

LEJEUNE, Philippe. Le pacte autobiographique. Paris: Seuil, 1975. (Col. Poétique)

TRAITS ET Portraits (Collection). [Texto de apresentação da coleção]. Colette Fellous (org.). Mercure de France [Site]. Disponível em: <http://www.mercuredefrance.fr/ collection-Traits_et_portraits-21-1-1-o-1.html>. Acesso em: out. 2017.

VILA-MATAS, Enrique. Bartleby y compañía. Barcelona: Anagrama, 2000.

VILA-MATAS, Enrique. Dublinesca. Barcelona: Seix Barral, $2010 a$.

VILA-MATAS, Enrique. Perder teorías. Barcelona: Seix Barral, 2o1ob.

VILA-MATAS, Enrique. Chet Baker piensa en su arte: ficción crítica. In: Chet Baker piensa en su arte. Barcelona: Debolsillo, 2011a, pp. 245-345.

VILA-MATAS, Enrique. Chet Baker pense à son art: fiction critique. Trad. André Gabastou. Paris: Mercure de France, 2011b. (Col. Traits et Portraits) 


\section{Enrique Vila-Matas, entre legível e ilegível... - 612}

BERGONZONI, Gisela. Vila-Matas pense à son art: entre l'âme et la bête, entre la critique et le récit. In: PARISOT, Yolaine; PLUVINET, Charline (orgs.). Pour un récit transnational. La fiction au défi de l'histoire immédiate. Rennes: Presses Universitaires de Rennes, 2016. 